\title{
Factors Impacting Survival Outcomes after Curative Resection for Primary Duodenal Adenocarcinoma
}

\author{
Masayuki Urabe ${ }^{1}$, Junichi Shindoh ${ }^{1,2^{*}}$, Yuta Kobayashi ${ }^{1}$, Satoshi Okubo ${ }^{1}$, Shusuke Haruta ${ }^{1}$, \\ Masaki Ueno ${ }^{1,2}$ and Masaji Hashimoto ${ }^{1,2}$
}

\author{
*Corresponding author: \\ Junichi Shindoh, M.D., Ph.D. \\ Department of Gastroenterological \\ Surgery, Toranomon Hospital \\ Okinaka Memorial Institute for Medical \\ Disease, 2-2-2 Toranomon, Minato-ku, \\ Tokyo 105-8470, Japan \\ Tel: +81-3-3588-1111 \\ Fax: +81-3-3560-7878 \\ E-mail: shindou-tky@umin.ac.jp
}

\section{Abbreviations:}

CEA - carcinoembryonic antigen;

$\mathrm{Cl}$ - confidence interval;

CRP - C-reactive protein;

HR - hazard ratio;

OS - overall survival;

PDA - primary duodenal adenocarcinoma RFS - relapse-free survival.
Received: 01.02.2020

Accepted: 10.04.2020

Copyright (c) Celsius Publishing House www.sgo-iasgo.com

\author{
'Department of Gastroenterological Surgery, Toranomon Hospital, 2-2-2 Toranomon, \\ Minato-ku, Tokyo 105-8470, Japan \\ ${ }^{2}$ Okinaka Memorial Institute for Medical Disease, 2-2-2 Toranomon, Minato-ku \\ Tokyo 105-8470, Japan

\section{ABSTRACT}

Background: Primary duodenal adenocarcinoma (PDA) is a rare gastrointestinal tumor and factors predicting survival outcomes after curative resection have yet to be fully elucidated. Methods: Applying the Cox proportional hazard model, we retrospectively evaluated associations between overall/relapse-free survivals (OS/RFS) and 18 clinicopathological factors in 33 patients who had undergone $\mathrm{R} 0$ resection for PDA.

Results: Univariate analysis revealed worsening RFS to be significantly related to pancreatic invasion, multiple nodal metastases, and the preoperative serum carcinoembryonic antigen level. Pancreatic invasion and multiple nodal metastases were also found to be significantly associated with poorer OS in the univariate analysis. In multivariate analysis, only pancreatic invasion was an independent predictor of OS (hazard ratio [HR] 5.27, 95\% confidence interval $[\mathrm{Cl}] 1.15-24.2, \mathrm{P}=0.033)$. As to RFS, both pancreatic invasion and multiple nodal metastases correlated independently with unfavorable outcomes (HR 42.8, 95\% Cl 3.59 - 510, $\mathrm{P}=0.003$; HR 216, $95 \% \mathrm{Cl} 6.86-6.8 \times 10^{3}, \mathrm{P}=0.002$; respectively). Only one of the 19 patients with PDA limited to the mucosal/submucosal layer developed recurrent disease (local site), while seven patients with pancreatic invasion and/or multiple nodal metastases all experienced metachronous distant recurrence.

Conclusion: While the likelihood of progression to systemic disease after meticulous surgical removal is very low in early-stage PDA, patients with PDA invading the pancreas and/or metastasizing to multiple lymph nodes are at high risk of developing distant relapse and may benefit from additional systemic therapy.

Key words: duodenal adenocarcinoma, pancreatoduodenectomy, pancreatic invasion, nodal metastasis, recurrence, survival

\section{INTRODUCTION}

Primary duodenal adenocarcinoma (PDA) is a rare gastrointestinal malignancy, reportedly accounting for $0.3 \%$ of all cancers involving the alimentary tract $(1,2)$. In addition to its low incidence, PDA is generally investigated and grouped with jejunal/ileal adenocarcinoma (3). Detailed information specifically regarding 
PDA-associated factors is hence limited. Complete surgical extirpation, when feasible, has long been deemed the optimal curative approach for PDA, with the possibility of achieving long-term postoperative survival. However, the best care during the perioperative term has yet to be established. In the present study, we assessed the clinical significance of key prognostic indicators with the aim of developing novel therapeutic strategies.

We retrospectively investigated clinicopathological characteristics of patients undergoing surgical resection with curative intent (RO) for PDA to identify which factors showed meaningful correlations with survival outcomes.

\section{PATIENTS AND METHODS}

\section{Study population}

We identified, from a database prospectively stored by the Department of Gastroenterological Surgery, Toranomon Hospital, 45 consecutive patients who had undergone surgery for PDA between July 1988 and September 2019. Those undergoing resection of carcinoma arising in the papilla of Vater $(n=3)$, surgical palliation (gastrojejunostomy bypass) ( $n=5), R 1 / R 2$ resection ( $n=2)$, emergency operations $(n=1)$ and/or with follow-up periods of less than four months $(n=1)$ were excluded from the analysis.

The remaining 33 cases were retrospectively reviewed and included in this investigation. All analyses carried out in the current study were in accordance with the ethical guidelines established by Toranomon Hospital. Informed consent from the patients was not necessary due to the retrospective design of this study.

\section{Clinicopathological data}

We thoroughly reviewed the subjects' medical records to obtain relevant clinical data. The necessary histological parameters, i.e. tumor location, histological grade, depth of tumor invasion, nodal metastasis, and lymphovascular involvement, were available for all subjects.

Preoperative examinations for elective abdominal surgery consist mainly of physical assessment, laboratory testing, esophagogastroduodenoscopy, endoscopic ultrasound, contrast-enhanced computed tomography, and, if necessary, positron-emission tomography with 18 F-fluorodeoxyglucose. The serum carcinoembryonic antigen (CEA) level had been measured within 30 days prior to surgery in all subjects. Preoperative blood hemoglobin, serum albumin and serum C-reactive protein levels were determined during the week before surgery. Cut-off values for each index used in the survival analyses were based on our institutional standards.

Routine postoperative surveillance included physical examination and blood testing at every visit. Esophagogastroduodenoscopy and contrast-enhanced computed tomography were also performed every 6 or 12 months, for up to 5 years postoperatively.

Postoperative complications were defined as those of grade II or greater severity, according to the ClavienDindo classification (4).

\section{Statistical analysis}

The Kaplan-Meier method was used to create survival curves. The log-rank test was applied to analyze differences between the curves. We calculated univariate and multivariate hazard ratios using the Cox proportional hazard model. Variables with $\mathrm{P}<0.1$ in the univariate analysis were included in the multivariate analysis. Overall survival (OS) calculations were from the date of surgery to the date of death from any cause, with censoring at the time of the last follow-up. Relapse-free survival (RFS) was calculated from the date of surgery to the date of recurrence or death, regardless of cause, with censoring at the time of the last follow-up.

Values of $\mathrm{P}<0.05$ (two-tailed) were considered significant for all analyses. All of the statistical analyses were carried out employing JMP Pro 14.2.0. (SAS Institute, Cary, NC).

\section{RESULTS}

\section{Patient and tumor characteristics}

The demographic variables of all 33 subjects are summarized in table 1 . There were 23 men and 10 women, with a median age of $68(50-86)$ years. The most frequent tumor location was the second portion of the duodenum $(20 / 33,60.6 \%)$. Tumor invasion was limited to the mucosal/submucosal layer in the majority of patients $(19 / 33,57.6 \%)$, while pancreatic invasion across the serosa was pathologically confirmed in six (18.2\%). Lymph node metastasis was documented in six patients $(18.2 \%)$, of whom three had multiple nodal metastases (9.1\%). Lymphovascular involvement was present in 18 patients (54.5\%). Seven (21.2\%), ten $(30.3 \%)$ and $16(48.5 \%)$ patients had undergone gastrectomies, partial duodenectomies and pancreatoduodenectomies, respectively. Only four cases (12.1\%) had been given adjuvant chemotherapy, oral 
Table 1- Baseline background variables of the patients

\begin{tabular}{|c|c|c|}
\hline $\mathrm{n}=\mathbf{3 3}$ & $\#$ & $\%$ \\
\hline \multicolumn{3}{|l|}{ Patient characteristics } \\
\hline Age at surgery (years), median (range) & \multicolumn{2}{|c|}{$68(50-86)$} \\
\hline \multicolumn{3}{|l|}{ Gender } \\
\hline Male & 23 & 69.7 \\
\hline Female & 10 & 30.3 \\
\hline \multicolumn{3}{|l|}{ Smoking habit } \\
\hline Absent & 12 & 36.4 \\
\hline Present & 21 & 63.6 \\
\hline \multicolumn{3}{|l|}{ Diabetes mellitus } \\
\hline Absent & 25 & 75.8 \\
\hline Present & 8 & 24.2 \\
\hline \multicolumn{3}{|l|}{ Tumor factors } \\
\hline \multicolumn{3}{|l|}{ Location } \\
\hline Part 1 & 6 & 18.2 \\
\hline Part 2 & 20 & 60.6 \\
\hline Part 3 & 7 & 21.2 \\
\hline \multicolumn{3}{|l|}{ Histological grade } \\
\hline Well-moderately differentiated & 21 & 63.6 \\
\hline Poorly-undifferentiated & 12 & 36.4 \\
\hline Size $(\mathrm{mm})$, median (range) & \multicolumn{2}{|c|}{$30(10-80)$} \\
\hline \multicolumn{3}{|l|}{ Depth of invasion } \\
\hline Mucosa-Submucosa & 19 & 57.6 \\
\hline Muscularis propria-Serosa & 8 & 24.2 \\
\hline Pancreatic invasion & 6 & 18.2 \\
\hline \multicolumn{3}{|l|}{ Nodal metastasis } \\
\hline None & 27 & 81.8 \\
\hline Singular & 3 & 9.1 \\
\hline Multiple & 3 & 9.1 \\
\hline \multicolumn{3}{|l|}{ Lymphovascular involvement } \\
\hline Absent & 15 & 45.5 \\
\hline Present & 18 & 54.5 \\
\hline \multicolumn{3}{|l|}{ Treatment modalities } \\
\hline \multicolumn{3}{|l|}{ Types of surgery } \\
\hline Gastrectomy & 7 & 21.2 \\
\hline Partial duodenectomy & 10 & 30.3 \\
\hline Pancreatoduodenectomy & 16 & 48.5 \\
\hline \multicolumn{3}{|l|}{ Postoperative complication(s) } \\
\hline Absent & 12 & 36.4 \\
\hline Present & 21 & 63.6 \\
\hline Postoperative stay (days), median (range) & & \\
\hline \multicolumn{3}{|l|}{ Adjuvant chemotherapy } \\
\hline Absent & 29 & 87.9 \\
\hline Present & 4 & 12.1 \\
\hline \multicolumn{3}{|l|}{ Preoperative laboratory data } \\
\hline Hemoglobin ( $\mathrm{g} / \mathrm{L})$, median (range) & 134 & \\
\hline Albumin ( $g / L)$, median (range) & & \\
\hline $\mathrm{CRP}(\mathrm{mg} / \mathrm{L})$, median (range) & & \\
\hline CEA (ng/mL), median (range) & 2.5 & \\
\hline
\end{tabular}

CRP - C-reactive protein, CEA - carcinoembryonic antigen tegafur-uracil in accordance with the results of randomized controlled trial for treatment of colorectal carcinoma (5): one with tumor invasion of the submucosa accompanied by a single nodal metastasis and three with pancreas-invading tumors but no metastasis to regional lymph nodes.

\section{Survival analysis using Kaplan-Meier methods}

After a median follow-up period of 44.5 (4.4-193.3) months, nine patients (27.3\%) experienced disease recurrence and there were 13 deaths (39.4\%), from various causes. There were no mortalities during the 30-day period after surgery. Kaplan-Meier analyses for OS and RFS focused on the following tumor factors: location, histological grade, tumor size, depth of invasion, nodal metastasis, and lymphovascular involvement.

Trichotomous analysis for tumor invasion depth yielded overall $P$ values far below the level of significance (OS P $=0.005$, RFS P < 0.001) (figure 1a). Notably, while patients with pancreatic invasion showed clearly unfavorable outcomes as compared to those free of such invasion, the differences between the survival curves of the other two groups did not reach statistical significance (mucosa-submucosa vs. muscularis propriaserosa, OS P $=0.99$, RFS P $=0.68$ ).

The analysis focused on nodal metastasis demonstrated that survival outcomes were significantly poorer when the tumor had metastasized to multiple lymph nodes $(\geq 2)$ (OS $P=0.002$, RFS $P<0.001$ ) (figure $1 b)$.

Other factors, including tumor location (part 1 vs. 2 vs. 3), histological grade (well-moderately differentiated vs. poorly-undifferentiated), size ( $\leq 30 \mathrm{mmvs}>30 \mathrm{~mm}$ ) and lymphovascular involvement (absent vs. present), showed no significant associations with OS/RFS based on the Kaplan-Meier estimations (supplemental figure S1).

\section{Univariate and multivariate Cox regression analyses for $O S$ and RFS}

To identify survival predictors in PDA patients, the cumulative OS/RFS rates were compared for 18 clinicopathological factors in total (table 2).

In univariate Cox regression analysis, depth of invasion (pancreatic invasion) was found to be significantly associated with both OS (hazard ratio [HR] 7.27, 95\% confidence interval $[\mathrm{Cl}] 1.86-28.5, \mathrm{P}=0.004$ ) and RFS (HR 27.2, 95\% Cl 5.30-139, P < 0.001). Nodal metastasis (more than one) also showed a statistically significant relationship with OS (HR 19.9, 95\% Cl 1.79- 
a

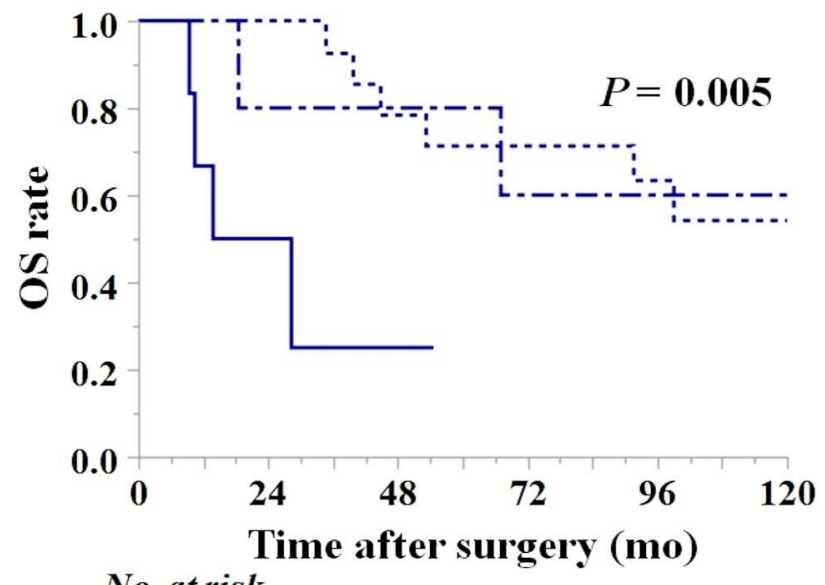

No. at risk

$\begin{array}{ccccccc}\cdots \cdots & 19 & 15 & 11 & 9 & 7 & 5 \\ -\cdots & 8 & 4 & 4 & 3 & 2 & 2 \\ - & 6 & 2 & 1 & - & - & -\end{array}$

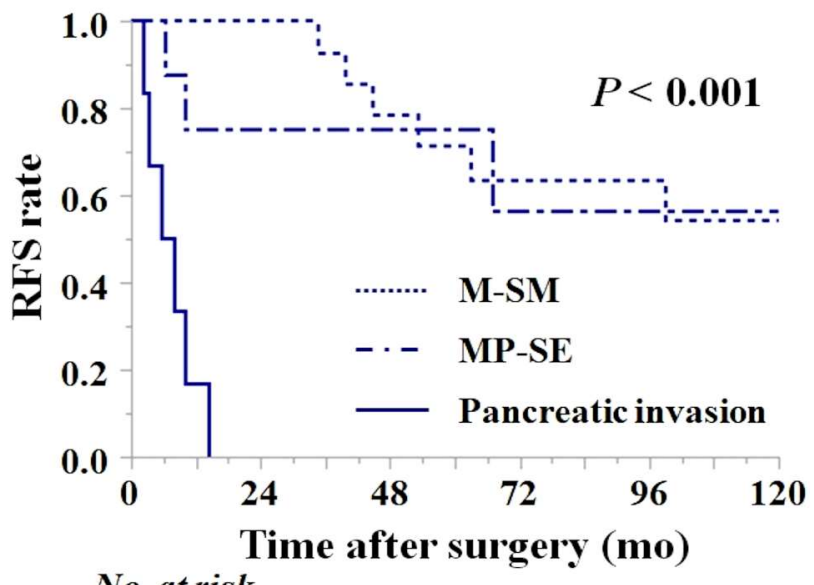

No. at risk

\begin{tabular}{|c|c|c|c|c|}
\hline …... 19 & 15 & 11 & 8 & \\
\hline$-\cdots 8$ & 4 & 4 & 3 & \\
\hline-6 & - & - & - & \\
\hline
\end{tabular}

b

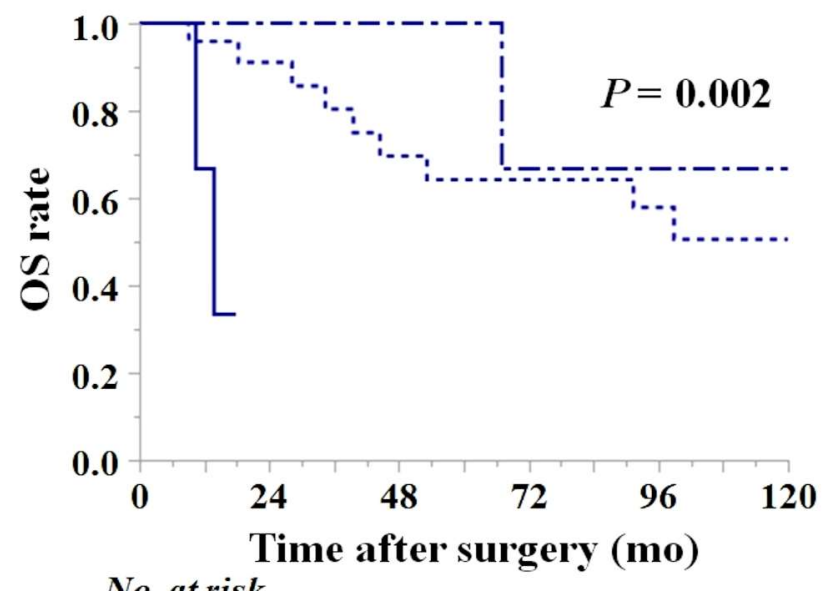

No. at risk

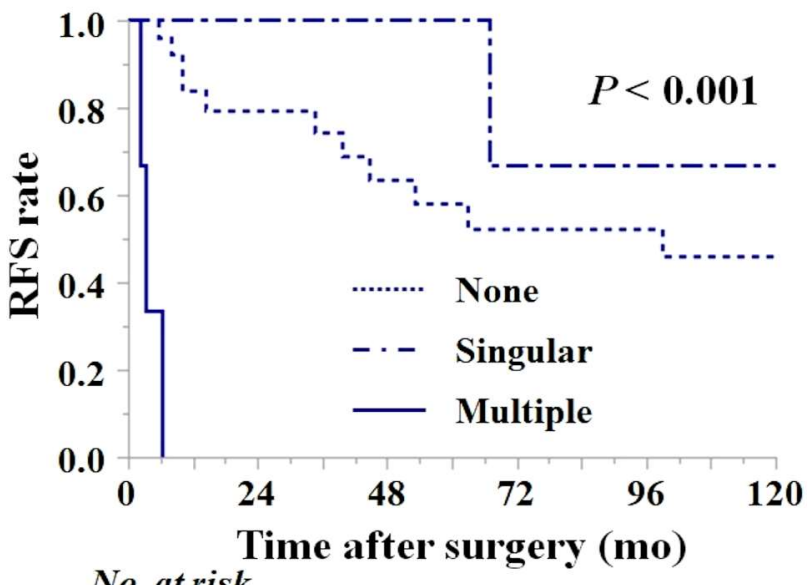

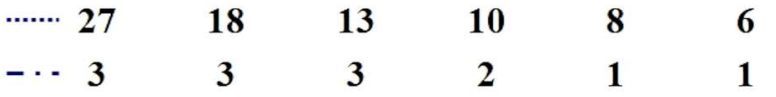

No. at risk

\begin{tabular}{|c|c|c|c|}
\hline …… 27 & 16 & 12 & S \\
\hline$-\cdots 3$ & 3 & 3 & \\
\hline-3 & - & - & \\
\hline
\end{tabular}

Figure 1 - Kaplan-Meier curves of overall survival (OS) and relapse-free survival (RFS) stratified according to (a) tumor invasion depth and (b) lymph node metastasis.

M mucosa, SM submucosa, MP muscularis propria, SE serosa

221, $\mathrm{P}=0.015$ ) as well as RFS (HR 58.9, 95\% Cl 5.90-589, $P<0.001)$. The univariate analysis revealed no significant relationships between OS and other factors, while the preoperative CEA level $(>5 \mathrm{ng} / \mathrm{mL})$ showed a significant correlation with RFS (HR 20.8, 95\% Cl 3.38$129, \mathrm{P}=0.001$ ).

In multivariate Cox regression analysis, only pancreatic invasion independently predicted OS reduction (HR 5.27, 95\% $\mathrm{Cl} 1.15-24.2, \mathrm{P}=0.033$ ). As to
RFS, pancreatic invasion and multiple nodal metastases remained independent factors ( $\mathrm{HR} 42.8,95 \% \mathrm{Cl} 3.59$ $510, \mathrm{P}=0.003$; HR 216, 95\% Cl 6.86-6.8 $\times 10^{3}, \mathrm{P}=0.002$; respectively).

\section{Pattern of recurrence}

Nine of our subjects had developed disease recurrence: five peritoneal metastases, two hepatic 


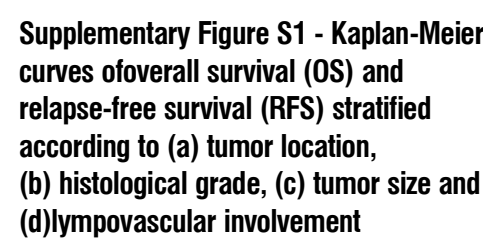

Supplementary Figure $\mathbf{S 1}$ - Kaplan-Meie curves ofoverall survival (OS) and relapse-free survival (RFS) stratified (d)lympovascular involvement
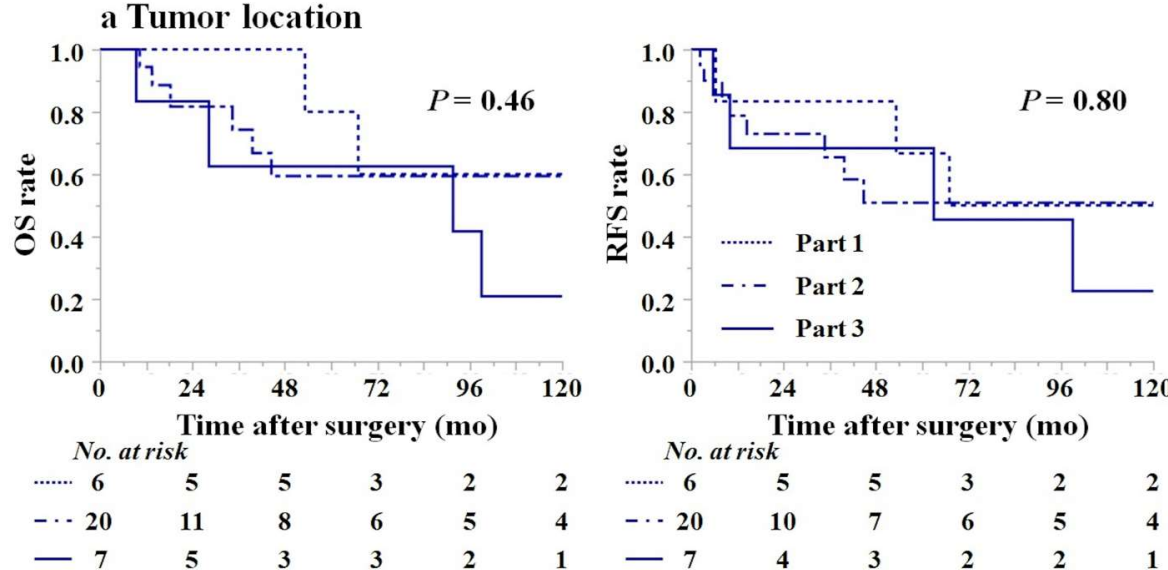

b Histological grade
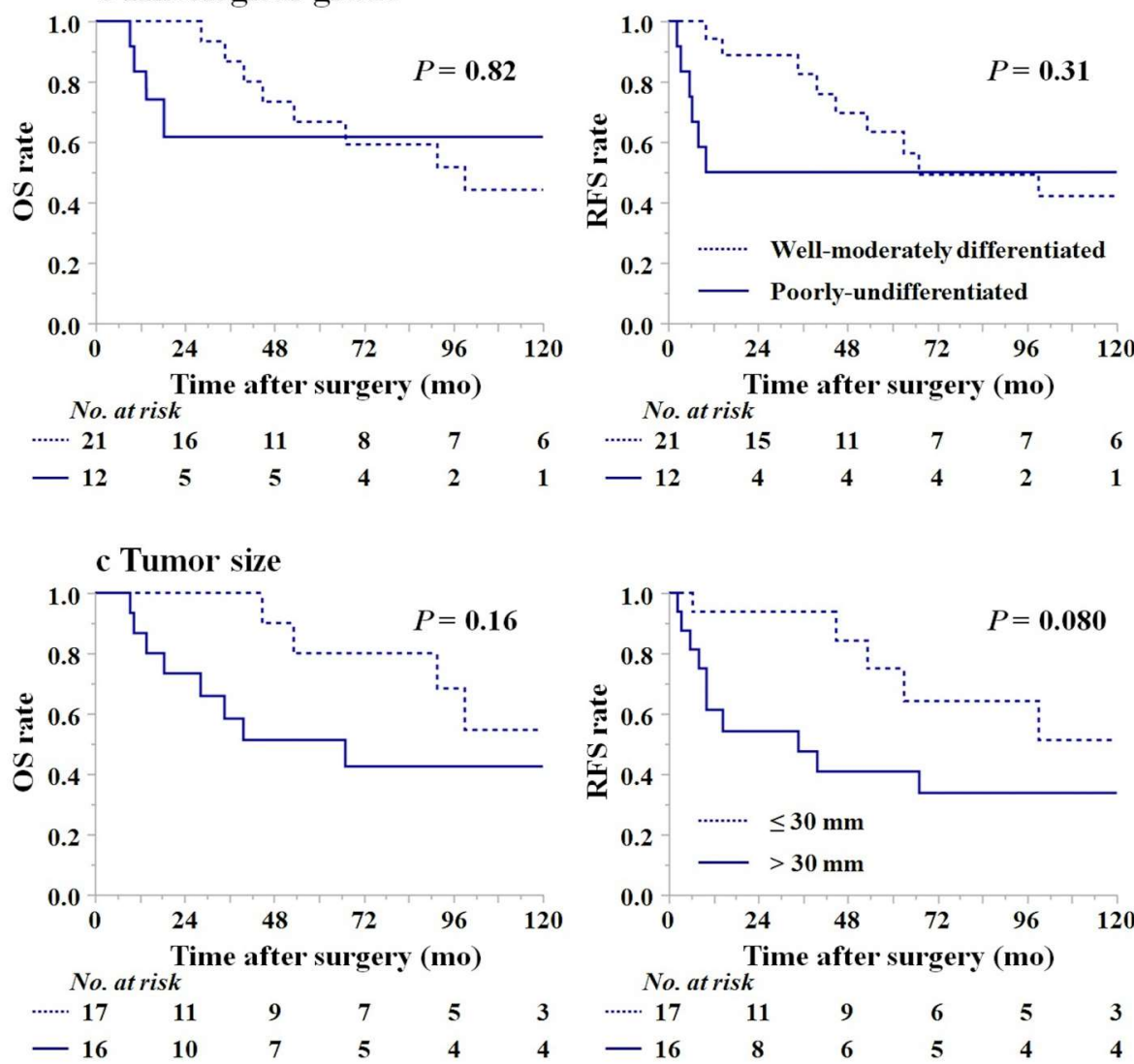

d Lymphovascular involvement
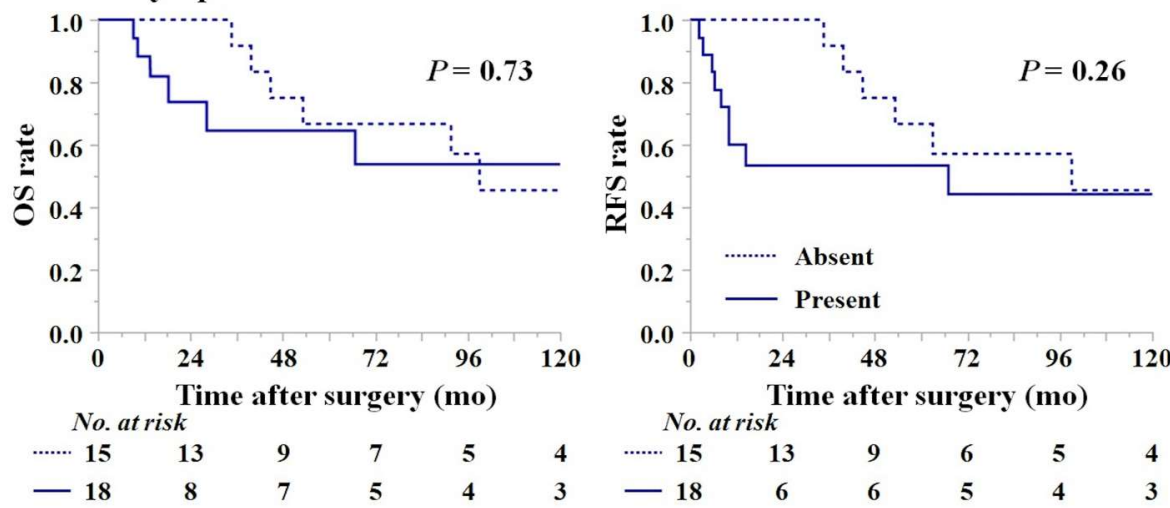
Table 2 - Univariate and multivariate Cox regression analyses for overall and relapse-free survival

\begin{tabular}{|c|c|c|c|c|c|c|c|c|}
\hline \multirow[t]{3}{*}{ Variables } & \multicolumn{4}{|c|}{ Overall survival } & \multicolumn{4}{|c|}{ Relapse-free survival } \\
\hline & \multicolumn{2}{|c|}{ Univariate } & \multicolumn{2}{|c|}{ Multivariate } & \multicolumn{2}{|c|}{ Univariate } & \multicolumn{2}{|c|}{ Multivariate } \\
\hline & $\begin{array}{c}\text { HR } \\
(95 \% \mathrm{CI})\end{array}$ & $P$ value & $\begin{array}{c}\mathrm{HR} \\
(95 \% \mathrm{CI})\end{array}$ & $P$ value & $\begin{array}{c}\mathrm{HR} \\
(95 \% \mathrm{CI})\end{array}$ & $P$ value & $\begin{array}{c}\mathrm{HR} \\
(95 \% \mathrm{CI})\end{array}$ & $P$ value \\
\hline Age at surgery (> 65 years) & $\begin{array}{c}1.92 \\
(0.51-7.18)\end{array}$ & 0.33 & & & $\begin{array}{c}1.73 \\
(0.55-5.49)\end{array}$ & 0.35 & & \\
\hline Gender (male) & $\begin{array}{c}0.95 \\
(0.29-3.18)\end{array}$ & 0.94 & & & $\begin{array}{c}1.38 \\
(0.44-4.36)\end{array}$ & 0.58 & & \\
\hline Smoking habit (present) & $\begin{array}{c}0.69 \\
(0.22-2.14)\end{array}$ & 0.52 & & & $\begin{array}{c}1.03 \\
(0.36-2.89)\end{array}$ & 0.96 & & \\
\hline Diabetes mellitus (present) & $\begin{array}{c}2.31 \\
(0.72-7.42)\end{array}$ & 0.16 & & & $\begin{array}{c}2.16 \\
(0.76-6.17)\end{array}$ & 0.15 & & \\
\hline Location (part 2) & $\begin{array}{c}0.81 \\
(0.26-2.54)\end{array}$ & 0.72 & & & $\begin{array}{c}0.92 \\
(0.33-2.55)\end{array}$ & 0.87 & & \\
\hline $\begin{array}{l}\text { Histological grade } \\
\text { (poorly-undifferentiated) }\end{array}$ & $\begin{array}{c}1.15 \\
(0.34-3.86)\end{array}$ & 0.82 & & & $\begin{array}{c}1.71 \\
(0.60-4.83)\end{array}$ & 0.31 & & \\
\hline Tumor size (> $30 \mathrm{~mm})$ & $\begin{array}{c}2.31 \\
(0.69-7.70)\end{array}$ & 0.17 & & & $\begin{array}{c}2.53 \\
(0.86-7.42)\end{array}$ & 0.091 & $\begin{array}{c}1.48 \\
(0.36-6.09)\end{array}$ & 0.59 \\
\hline Depth of invasion (pancreas) & $\begin{array}{c}7.27 \\
(1.86-28.5)\end{array}$ & 0.004 & $\begin{array}{c}5.27 \\
(1.15-24.2)\end{array}$ & 0.033 & $\begin{array}{c}27.2 \\
(5.30-139)\end{array}$ & $<0.001$ & $\begin{array}{c}42.8 \\
(3.59-510)\end{array}$ & 0.003 \\
\hline Nodal metastasis (multiple) & $\begin{array}{c}19.9 \\
(1.79-221)\end{array}$ & 0.015 & $\begin{array}{c}8.61 \\
(0.70-106)\end{array}$ & 0.093 & $\begin{array}{c}58.9 \\
(5.90-589)\end{array}$ & $<0.001$ & $\begin{array}{c}216 \\
\left(6.86-6.8 \times 10^{3}\right)\end{array}$ & 0.002 \\
\hline $\begin{array}{l}\text { Lymphovascular involvement } \\
\text { (present) }\end{array}$ & $\begin{array}{c}1.23 \\
(0.39-3.83)\end{array}$ & 0.73 & & & $\begin{array}{c}1.81 \\
(0.64-5.13)\end{array}$ & 0.27 & & \\
\hline $\begin{array}{l}\text { Types of surgery } \\
\text { (pancreatoduodenectomy) }\end{array}$ & $\begin{array}{c}0.90 \\
(0.27-3.02)\end{array}$ & 0.87 & & & $\begin{array}{c}1.10 \\
(0.39-3.15)\end{array}$ & 0.85 & & \\
\hline $\begin{array}{l}\text { Postoperative complication(s) } \\
\text { (present) }\end{array}$ & $\begin{array}{c}1.41 \\
(0.42-4.71)\end{array}$ & 0.58 & & & $\begin{array}{c}0.92 \\
(0.33-2.59)\end{array}$ & 0.87 & & \\
\hline Postoperative stay (> 30 days) & $\begin{array}{c}2.15 \\
(0.68-6.82)\end{array}$ & 0.19 & & & $\begin{array}{c}1.71 \\
(0.62-4.73)\end{array}$ & 0.30 & & \\
\hline $\begin{array}{l}\text { Adjuvant chemotherapy } \\
\text { (present) }\end{array}$ & $\begin{array}{c}2.04 \\
(0.44-9.44)\end{array}$ & 0.36 & & & $\begin{array}{c}2.38 \\
(0.66-8.50)\end{array}$ & 0.18 & & \\
\hline $\begin{array}{l}\text { Preoperative hemoglobin } \\
(>140 \mathrm{~g} / \mathrm{L})\end{array}$ & $\begin{array}{c}1.68 \\
(0.52-5.39)\end{array}$ & 0.38 & & & $\begin{array}{c}1.59 \\
(0.56-4.51)\end{array}$ & 0.39 & & \\
\hline $\begin{array}{l}\text { Preoperative albumin } \\
(>40 \mathrm{~g} / \mathrm{L})\end{array}$ & $\begin{array}{c}2.14 \\
(0.64-7.11)\end{array}$ & 0.22 & & & $\begin{array}{c}1.46 \\
(0.52-4.10)\end{array}$ & 0.47 & & \\
\hline $\begin{array}{l}\text { Preoperative CRP } \\
(>2 \mathrm{mg} / \mathrm{L})\end{array}$ & $\begin{array}{c}0.22 \\
(0.03-1.69)\end{array}$ & 0.14 & & & $\begin{array}{c}0.17 \\
(0.022-1.27)\end{array}$ & 0.083 & $\begin{array}{c}0.060 \\
\left(3.2 \times 10^{-3}-1.13\right)\end{array}$ & 0.060 \\
\hline $\begin{array}{l}\text { Preoperative CEA } \\
(>5 \mathrm{ng} / \mathrm{mL})\end{array}$ & $\begin{array}{c}1.76 \\
(0.22-14.2)\end{array}$ & 0.60 & & & $\begin{array}{c}20.8 \\
(3.38-129)\end{array}$ & 0.001 & $\begin{array}{c}1.94 \\
(0.15-24.7)\end{array}$ & 0.61 \\
\hline
\end{tabular}

HR - hazard ratio, $\mathrm{Cl}$ - confidence interval, CRP - C-reactive protein, CEA - carcinoembryonic antigen

metastases, one lymph node metastasis and one local site relapse (fig. 2). It is noteworthy that recurrent disease (local site) was reported in only one of the 19 patients with mucosa/submucosa-invading PDA (1/19, $5.3 \%)$, while all six with pancreatic invasion experienced distant recurrence (five peritoneal and one hepatic) $(6 / 6,100 \%)$ and five died of their disease. Similarly, all three patients with multiple nodal metastases (two with pancreatic invasion) developed metachronous disease (two peritoneal and one nodal) $(3 / 3,100 \%)$.

\section{DISCUSSION}

We assessed clinicopathological factors possibly influencing the outcomes of patients undergoing RO resection of PDA. This retrospective study revealed pancreatic invasion and multiple lymph node metastases to be independent predictors of poorer survival outcomes. Of note, all of the patients with pancreatic invasion and/or multiple nodal metastases $(n=7)$ ultimately developed distant metachronous recurrence. This observation suggests PDA to possibly be in the systemic phase characterized by invasion of the pancreas and/or metastasis to multiple lymph nodes. Thus, in such a population, perioperative systemic therapy in addition to conventional surgical resection might well be warranted.

Regarding therapeutic strategies, controversy persists as to how to improve the clinical outcomes of high-risk populations susceptible to recurrent disease. Despite previously reported contradictory results $(6,7)$, recent lines of retrospective evidence have 


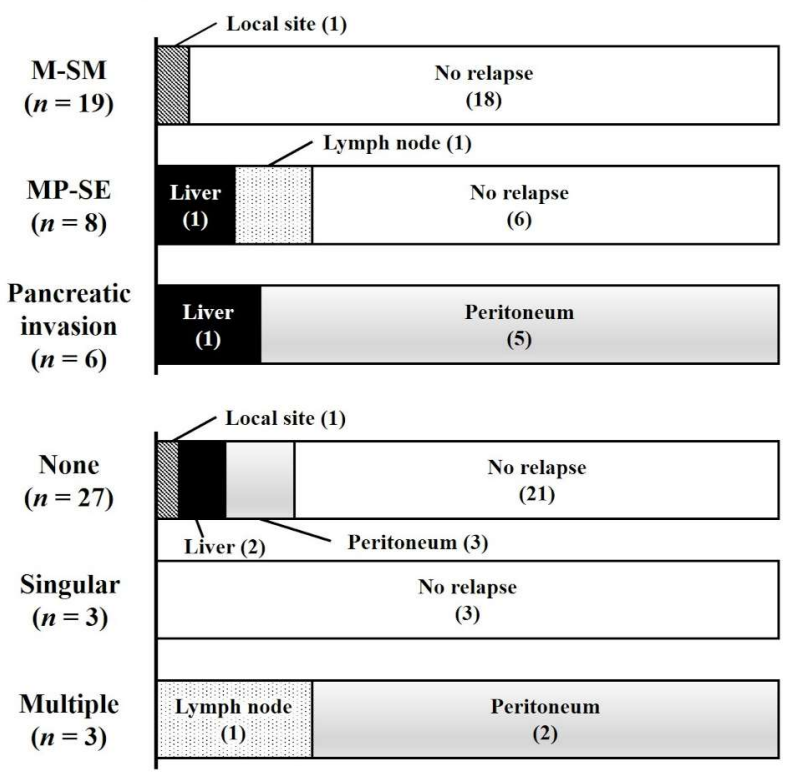

Figure 2 - Recurrence pattern according to (a) tumor invasion depth and (b) lymph node metastasis. Nine recurrent diseases included five peritoneal, two hepatic, one nodal and one local site relapse.

M mucosa, SM submucosa, MP muscularis propria, SE serosa

suggested that adjuvant chemotherapy, mainly regimens employing oxaliplatin with either infusional 5-fluorouracil or capecitabine, may provide survival benefits for patients with lymph node-positive PDA (810). Furthermore, a large-scale randomized controlled trial (ESPAC-3) showed adjuvant chemotherapy (fluorouracil plus folinic acid or gemcitabine) to yield a significant survival benefit, although results specific to PDA were limited (11). Adjuvant chemoradiation reportedly improved locoregional control after surgery for PDA in some studies (12-15), while another group documented adjuvant chemoradiation to neither decrease local recurrence nor prolong overall survival (16). The role of preoperative chemotherapy remains to be determined, as this approach is supported by no more than a few case series (17-19). As yet, we have no standardized evidence supporting the concept of perioperative chemotherapy/chemoradiotherapy prolonging OS in patients with PDA. To improve the survivals of patients with advanced PDA, additional prospective evidence relating to the role of systemic therapy is eagerly awaited.

Our results also raise the possibility of there being little risk of PDA relapsing systemically when the primary tumor is limited to the mucosal/submucosal layer and is therefore deemed potentially curable, assuming complete surgical RO resection. To fully extirpate an early-stage PDA, pancreatoduodenectomy is frequently required to achieve complete tumor removal because this tumor frequently originates in the second portion of the duodenum adjacent to the pancreas $(17,20,21)$. Pancreatoduodenectomy is both highly invasive and complex, carrying a high mortality/morbidity rate (reported hospital mortality 1.7\%)(21-23). The indications for pancreatoduodenectomy as a procedure for treating PDA thus remain controversial (24-28). In the current study, the 16 pancreatoduodenectomies performed were not associated with short-term mortality and the survival rate was comparable to that of a cohort undergoing other procedures (table 2). However, the rate of postoperative complications (mainly delayed gastric emptying) was significantly higher than in the nonpancreatoduodenectomy group (13/16 vs. $8 / 17, \mathrm{P}=$ 0.041 , by the chi-squared test). Pancreatoduodenectomy is acceptable if it is the only surgical intervention allowing complete tumor removal. If other options are available, however, the indications for pancreatoduodenectomy should be carefully considered.

As to non-tumor factors, only the preoperative CEA level (> $5 \mathrm{ng} / \mathrm{mL}$ ) was significantly associated with RFS in our univariate analysis, but this factor lost independence in the multivariate analysis (table 2). Though the prognostic significance of the CEA level is widely accepted and this factor is routinely measured preoperatively in colon cancer cases (29), its predictive value in PDA remains uncertain.

Limitations of the present study include its retrospective nature and the relatively small number of subjects. However, surgical managements were highly consistent during the study period because the operations had all been performed by the same surgical team at our tertiary institution. Also, the current study is based on a prospectively collected database registering consecutive patients with follow-up of sufficient duration. Although further validation with a larger sample size is needed before definite conclusions can be drawn, we hope that our observations will contribute to establishing optimal therapeutic strategies for operable PDA.

\section{CONCLUSION}

We aimed to retrospectively identify key survival factors in patients who had received curative resection of PDA. Patients with PDA limited to the mucosa/submucosa rarely showed progression to systemic disease. Meticulous operative approaches, despite being highly invasive, may provide curative treatment for such PDA patients. On the other hand, patients with unfavorable 
tumor features, such as pancreatic invasion and/or multiple lymph node metastases, were highly likely to develop distant relapse even after R0 extirpation of the tumor and may benefit from additional systemic therapy.

\section{Ethical approval}

This study was approved by the ethics committee of Toranomon Hospital. All procedures performed in studies involving human participants were in accordance with the ethical standards of the institutional and/or national research committee and with the 1964 Helsinki Declaration and its later amendments or comparable ethical standards.

\section{Acknowledgements}

None to declare.

\section{Conflicts of interest}

The authors declare that they have no potential conflicts of interest to disclose.

\section{Source of funding}

No specific grants were received from funding agencies in the public, commercial, or not-for-profit sectors for this research.

\section{Author contributions}

M. Urabe and J. Shindoh contributed to the design of the study and drafting of the article. All authors contributed to acquisition, analysis and interpretation of data. Y. Kobayashi, S. Okubo and S. Haruta revised the article critically for important intellectual content. $M$. Ueno and $M$. Hashimoto contributed to final approval of the to-be-submitted version.

\section{REFERENCES}

1. Moss WM, McCart PM, Juler G, Miller DR. Primary adenocarcinoma of the duodenum. Arch Surg 1974;108(6):805-807.

2. Spira IA, Ghazi A, Wolff WI. Primary adenocarcinoma of the duodenum. Cancer 1977;39(4):1721-1726.

3. Bosman FT, Carneiro F, Hruban RH, Theise ND. WHO Classification of tumours of the digestive system, 4th ed.; International agency for research on cancer (IARC): Lyon, France; 2010.

4. Dindo D, Demartines N, Clavien PA. Classification of surgical complications: a new proposal with evaluation in a cohort of 6336 patients and results of a survey. Ann Surg 2004;240(2):205-213.

5. Akasu T, Moriya Y, Ohashi Y, Yoshida S, Shirao K, Kodaira S. Adjuvant chemotherapy with uracil-tegafur for pathological stage III rectal cancer after mesorectal excision with selective lateral pelvic lymphadenectomy: a multicenter randomized controlled trial. Jpn J Clin Oncol 2006;36(4):237-244.

6. Dabaja BS, Suki D, Pro B, Bonnen M, Ajani J. Adenocarcinoma of the small bowel: presentation, prognostic factors, and outcome of 217 patients. Cancer 2004;101(3):518-526.

7. Hirashita T, Ohta M, Tada K, Saga K, Takayama H, Endo Y, et al. Prognostic factors of non-ampullary duodenal adenocarcinoma. Jpn J Clin Oncol 2018;48(8):743-747.

8. Ecker BL, McMillan MT, Datta J, Mamtani R, Giantonio BJ, Dempsey
DT, et al. Efficacy of adjuvant chemotherapy for small bowel adenocarcinoma: a propensity score-matched analysis. Cancer 2016;122(5): 693-701.

9. Ecker BL, McMillan MT, Datta J, Lee MK, Karakousis GC, Vollmer CM $\mathrm{Jr}$., et al. Adjuvant chemotherapy versus chemoradiotherapy in the management of patients with surgically resected duodenal adenocarcinoma: a propensity score-matched analysis of a nationwide clinical oncology database. Cancer 2017;123(6):967-976.

10. Overman MJ, Kopetz S, Lin E, Abbruzzese JL, Wolff RA. Is there a role for adjuvant therapy in resected adenocarcinoma of the small intestine. Acta Oncol 2010;49(4):474-479.

11. Neoptolemos JP, Moore MJ, Cox TF, Valle JW, Palmer DH, McDonald $\mathrm{AC}$, et al. Effect of adjuvant chemotherapy with fluorouracil plus folinic acid or gemcitabine vs observation on survival in patients with resected periampullary adenocarcinoma: the ESPAC-3 periampullary cancer randomized trial. JAMA 2012;308(2):147-156.

12. Kelsey CR, Nelson JW, Willett CG, Chino JP, Clough RW, Bendell JC, et al. Duodenal adenocarcinoma: patterns of failure after resection and the role of chemoradiotherapy. Int J Radiat Oncol Biol Phys 2007; 69(5):1436-1441.

13. Swartz MJ, Hughes MA, Frassica DA, Herman J, Yeo CJ, Riall TS, et al. Adjuvant concurrent chemoradiation for node-positive adenocarcinoma of the duodenum. Arch Surg 2007;142(3):285-288.

14. Kim K, Chie EK, Jang JY, Kim SW, Oh DY, Im SA, et al. Role of adjuvant chemoradiotherapy for duodenal cancer: a single center experience. Am J Clin Oncol 2012;35(6):533-536.

15. Jang BS, Park HJ, Kim K, Jang JY, Kim SW, Oh DY, et al. Role of adjuvant chemoradiotherapy for duodenal cancer: an updated analysis of long-term follow-up from single institution. World J Surg 2018:42(10):3294-3301.

16. Poultsides GA, Huang LC, Cameron JL, Tuli R, Lan L, Hruban RH, et al. Duodenal adenocarcinoma: clinicopathologic analysis and implications for treatment. Ann Surg Oncol 2012:19(6):1928-1935.

17. Hung FC, Kuo CM, Chuah SK, Kuo CH, Chen YS, Lu SN, et al. Clinical analysis of primary duodenal adenocarcinoma: an 11-year experience. J Gastroenterol Hepatol 2007;22(5):724-728.

18. Manfredi S, Thiebot T, Henno S, Falize L, Bretagne JF, Meunier B. Complete response of an initially non-surgical adenocarcinoma of the duodenum to chemotherapy with the FOLFOX 4 regimen. J Gastrointest Surg 2009;13(12):2309-2313.

19. Bakaeen FG, Murr MM, Sarr MG, Thompson GB, Farnell MB, Nagorney DM, et al. What prognostic factors are important in duodenal adenocarcinoma? Arch Surg 2000;135(6):635-641.

20. Onkendi EO, Boostrom SY, Sarr MG, Farnell MB, Nagorney DM, Donohue JH, et al. 15-year experience with surgical treatment of duodenal carcinoma: a comparison of periampullary and extra-ampullary duodenal carcinomas. J Gastrointest Surg 2012;16(4):682-691.

21. Solaini L, Jamieson NB, Metcalfe M, Abu Hilal M, Soonawalla Z, Davidson BR, et al. Outcome after surgical resection for duodenal adenocarcinoma in the UK. Br J Surg 2015;102(6):676-681.

22. Cameron JL, He J. Two thousand consecutive pancreaticoduodenectomies. J Am Coll Surg 2015;220(4):530-536.

23. Rotman N, Pezet D, Fagniez PL, Cherqui D, Celicout B, Lointier P. Adenocarcinoma of the duodenum: factors influencing survival. French Association for Surgical Research. Br J Surg 1994;81(1):83-85.

24. Lee HG, You DD, Paik KY, Heo JS, Choi SH, Choi DW. Prognostic factors for primary duodenal adenocarcinoma. World $\mathrm{J}$ Surg 2008;32(10):2246-2252.

25. Dorcaratto D, Heneghan HM, Fiore B, Awan F, Maguire D, Geoghegan $\mathrm{J}$, et al. Segmental duodenal resection: indications, surgical techniques and postoperative outcomes. J Gastrointest Surg 2015;19(4):736-742.

26. Hashimoto D, Arima K, Chikamoto A, Taki K, Inoue R, Kaida T, et al. Limited resection of the duodenum for nonampullary duodenal tumors, with review of the literature. Am Surg 2016;82(11):11261132.

27. Sakamoto T, Saiura A, Ono Y, Mise $Y$, Inoue $Y$, Ishizawa T, et al. Optimal lymphadenectomy for duodenal adenocarcinoma: does the number alone matter? Ann Surg Oncol2017;24(11):3368-3375.

28. Cloyd JM, Norton JA, Visser BC, Poultsides GA. Does the extent of resection impact survival for duodenal adenocarcinoma? Analysis of 1,611 cases. Ann Surg Oncol 2015;22(2):573-580.

29. Thirunavukarasu $P$, Sukumar $S$, Sathaiah M, Mahan M, Pragatheeshwar KD, Pingpank JF, et al. C-stage in colon cancer: implications of carcinoembryonic antigen biomarker in staging, prognosis, and management. J Natl Cancer Inst 2011;103(8):689-697. 